\title{
Postharvest quality response of broccoli florets to combined application of 1-methylcyclopropene and modified atmosphere packaging
}

\author{
Ferhan K. Sabir \\ University of Selcuk, Faculty of Agriculture, Department of Horticulture, 42075, Konya, Turkey \\ e-mail: fkbasmaci@selcuk.edu.tr
}

\begin{abstract}
Broccoli is rich in health-promoting compounds such as ascorbic acid and glucosinolates. However, amount of such compounds inevitably decrease along with the storage. This study was conducted to investigate the effects of 1-methylcyclopropene (1-MCP) and Modified Atmosphere Packaging (MAP) treatments alone or in combination on postharvest life and quality of broccoli heads during cold storage. MAP and 1-MCP+MAP significantly reduced weight loss, delayed surface color changes and chlorophyll breakdown, maintained visual quality, ascorbic acid, total phenol, soluble solid contents and titratable acidity compared with control as well as 1-MCP treatment. In 1-MCP plus MAP treated florets, approximate $47 \%$ and more chlorophyll and $24 \%$ more total phenol contents were found compared to control florets. 1-MCP plus MAP application better performed in maintaining the quality of broccoli florets during 28-day-storage. Overall results revealed that combined treatment can be recommended for commercial broccoli storage at $0{ }^{\circ} \mathrm{C}$.
\end{abstract}

Key words: Broccoli, 1-MCP, MAP, quality, storage

\section{Introduction}

Fresh fruits and vegetables have important nutritional and economic values. Especially the consumption of Brassica genus vegetables is recommended to reduce the incidence of human cancer (Rangavajyhyala et al. 1998). Broccoli (Brassica oleracea var. italica) is a Brassica genus vegetable with high nutritional value due to its richness in vitamins, antioxidants, anti-carcinogenic substance and health promoting phytochemicals such as glucosinolates (Nestle 1998, Yuan et al. 2010). But the previous studies revealed that levels of ascorbic acid, glucosinolates and flavonoids have been significantly influenced during harvest, handling and storage (Vallejo et al. 2003, Nath et al. 2011).

Broccoli is a highly perishable vegetable that senesces quickly after harvest and thus its postharvest life is quite short due to yellowing, softening, water loss, decay and off-odor incidences (Forney et al. 2003, Vasconcelos and Almeida 2003). The green color of broccoli is an important quality feature for consumers. The loss of green color in broccoli florets occurs due to chlorophyll breakdown and this is stimulated by exogenously applied and endogenously produced ethylene (Tian et al. 1994, Ku and Wills 1999). Different chemical applications such as aminoethoxyvinylglycine (AVG) or silver ion were used to prevent yellowing (Wang 1977, Aharoni et al. 1985). However, these compounds to prevent yellowing has had limited commercial application as they are not registered for use on broccoli (Ku and Wills 1999). Recently, 1-methylcyclopropene (1-MCP) has been widely used for maintaining postharvest quality of horticultural commodities. 1-MCP is an ethylene action inhibitor that binds to the ethylene receptors and thereby delays ripening of products and extending storage life (Blankenship and Dole 2003). 1-MCP treatment inhibited the increase of respiration ratio and ethylene production (Ku and Wills 1999, Fan and Mattheis 2000), delayed yellowing and extended storage life of broccoli (Forney et al. 2003, Yuan et al. 2010). Yuan et al. (2010) also further emphasized that 1-MCP treatment reduced loss of health-promoting compounds such as glucosinolates or ascorbic acid in broccoli during 5 day-storage at $20^{\circ} \mathrm{C}$. Cefola et al. (2010) found that use of 1-MCP markedly extended the shelf life, reducing postharvest deterioration in broccoli raab florets.

Modified atmosphere packaging (MAP) is a technique used for prolonging the postharvest life of fresh fruits and vegetable. MAP can be defined as an alteration in the composition of gases in and around fresh produce by respiration and transpiration in package (Thompson 2003). Composition of the gas inside the package is changed by respiration of fruits, decreasing $\mathrm{O}_{2}$ level while $\mathrm{CO}_{2}$ increases during storage. Storage of broccoli in MAP reduced weight loss and respiration rate, maintained ascorbic acid, total antioxidant activity, glucosinolate contents and visual quality and thus increased postharvest life in cold or ambient storage (Nath et al. 2011, Serrano et al. 2006, Jia et al. 2009). 
Several researchers have reported that 1-MCP treatment is more effective when used in combination with MAP compared to single use of MAP or 1-MCP in litchi, persimmon, banana and tomato (Jiang et al. 1999, De Reuck et al. 2009, Kaynas et al. 2010, Oz 2011, Sabir and Agar 2011a).

The objective of this study was to investigate the effects of 1-MCP and MAP treatments alone or in combination on postharvest life and quality of broccoli during storage at $0^{\circ} \mathrm{C}$.

\section{Material and Methods \\ Material}

Broccoli heads (Brassica oleracea var. italica cv. 'Lucky') were obtained from local producers in Tarsus (Mersin Province) and then immediately transferred to Postharvest Laboratory of Horticulture Department, Selcuk University. A total of 240 undamaged and uniformly green heads were sorted randomly dividing into four equal lots.

\section{Treatments and storage}

Two lots of broccoli florets were placed in sealed air-tight plastic containers and exposed to $1 \mu \mathrm{I}^{-1} 1-\mathrm{MCP}(0.14 \%$ active ingredient). SmartFresh ${ }^{\mathrm{TM}}$ powder (AgroFresh, Inc., Dow Agroscinces, Philadelphia, PA, USA) was weighted out into a test tube and afterwards, warm distilled water was added to release 1-MCP gas. After shaking, the tube was placed in the container and then the florets were immediately hermetically sealed and maintained for 12 $\mathrm{h}$ at $20^{\circ} \mathrm{C}$. Control florets were kept under the same conditions in containers without 1-MCP. After applications, containers were opened and the florets were led to ventilate. The first lot of the 1-MCP treated florets was stored in MAP (1-MCP+MAP treatment) while the second lot was placed in to open plastic boxes (1-MCP). As to the untreated florets, the first lot was stored in open plastic boxes without any application (as control) while the second was packed with Xtend ${ }^{\circ}$ (StePac, Israel) MAPs (MAP; $\mathrm{CO}_{2}$ transmission rate [TR]: $2203 \mathrm{cc} \mathrm{m}^{-2}$ day $^{-1}$ and water vapour [WV] TR: $150.0 \mathrm{~g} \mathrm{~m}^{-2} \mathrm{day}^{-1}$ at $23^{\circ} \mathrm{C}$ ). All the samples were stored at $0{ }^{\circ} \mathrm{C}$ and $95 \% \mathrm{RH}$ for 28 days. Initially and 7,14 , 21 and 28 days after storage, samples were analyzed to assess postharvest quality changes as described below.

\section{Color measurement}

The surface color of florets ( $\mathrm{L} * \mathrm{a} * \mathrm{~b} *$ system) was measured with a chromameter (Minolta CR400, Osaka, Japan) during the period of storage. Three broccoli florets from each treatment were assayed and measurements were taken from five different points per floret. The hue angle $\left(h^{\circ}\right)$ was calculated $a h^{\circ}=\tan ^{-1}(b / a)$, when $a>0$ and $b>0$, or as $\mathrm{h}^{\circ}=180^{\circ}+\tan ^{-1}(\mathrm{~b} / \mathrm{a})$ when $\mathrm{a}<0$ and $\mathrm{b}>0$ (Lancaster et al. 1997).

\section{Weight loss}

The heads were weighted after postharvest treatment and during storage at 7, 14, 21 and 28 days. Results were expressed as percentage of weight loss relative to the initial weight.

\section{Total phenol content}

Total phenol content of broccoli florets was determined as previously described by Singleton et al. (1999) with slight modifications. An aliquot $(0.1 \mathrm{ml})$ of broccoli extract was added $6.0 \mathrm{ml}$ distilled water, followed by $0.5 \mathrm{ml}$ Folin-Ciocalteu reagent. Solutions were swirl to mix and incubate $3 \mathrm{~min}$ at room temperature. After incubation, $1.5 \mathrm{ml} 20 \% \mathrm{Na}_{2} \mathrm{CO}_{3}$ supplemented and the volume was made up $10 \mathrm{ml}$ distilled water. After $2 \mathrm{~h}$ incubate at $25^{\circ} \mathrm{C}$, the absorbance was measured at $760 \mathrm{~nm}$ and the total phenolic content was calculated using gallic acid as standard. Results were expressed as $\mathrm{mg}_{\text {gallic acid }} \mathrm{kg}^{-1}$.

\section{Ascorbic acid}

Broccoli florets were blended with a high speedy warring blender at $3 \mathrm{~min} .5 \mathrm{~g}$ blended sample was mixed with $45 \mathrm{ml} \mathrm{0.4 \%} \mathrm{oxalic} \mathrm{acid} \mathrm{and} \mathrm{then} \mathrm{filtered} \mathrm{via} \mathrm{filter} \mathrm{paper.} \mathrm{One} \mathrm{milliliter} \mathrm{filtrate} \mathrm{and} 9 \mathrm{ml}$ 2,6- dichlorophenolindophenol sodium salt were mixed then the transmittance value was measured $520 \mathrm{~nm}$ using UV spectrophotometer. Blank were prepared in the same way but using $1 \mathrm{ml}$ filtrate and $9 \mathrm{ml}$ distilled water. Results were expressed as mg $100 \mathrm{~g}^{-1}$ (Ozdemir and Dundar 2006). 


\section{Total chlorophyll}

Total chlorophyll content of broccoli was determined by a spectrophotometric method (Sabir and Agar 2011b). One gram blended broccoli portions were homogenized with $10 \mathrm{ml}$ chloroform:methanol $(2: 1, \mathrm{v} / \mathrm{v})$ for 1 min. Extracts were filtered with filter paper. The residue was resuspended in $10 \mathrm{ml}$ chloroform:methanol and then filtered. All the filtrates were combined and solutions were supplemented with chloroform:methanol to $25 \mathrm{ml}$ final volume. Total chlorophyll was determined by measuring absorbance of solution in UV spectrophotometer at 663 and 645 $\mathrm{nm}$ against chloroform:methanol blank. The total chlorophyll was estimated by the following formula.

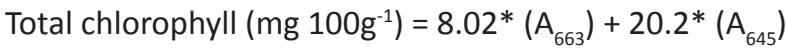

\section{Titratable acidity (TA) and soluble solid content (SSC)}

Broccoli florets were squeezed for SSC and TA determination. SSC was determined using a refractometer (Atago, Tokyo, Japan) and expressed as \%. TA was estimated by titrating $5 \mathrm{ml}$ juice with $0.1 \mathrm{~N} \mathrm{NaOH}$ to a pH end point of 8.1 and expressed as percentage of citric acid.

\section{Visual quality and color}

During storage, broccoli heads were evaluated by panelist for visual quality using 1-9 scale described by Yuan et al. (2010) where 9 refers to excellent and fresh appearance, 7 to good, 5 to fair (limit of marketability), 3 to fair (useable but not saleable), and 1 to unusable. Color of broccoli florets was visually scored using 1-5 scale as described by Jia et al. (2009), where 1 refers to dark green, 2 to trace yellow ( $10 \%$ yellow), 3 to slightly yellow ( $25 \%$ yellow), 4 to medium yellow ( $50 \%$ yellow), 5 to completely yellow (100\%). The panelists were asked to consider initial color and general head quality (compactness of heads and hardness of stem texture) of the produce while evaluating the samples for each experimental date.

\section{Statistical analysis}

Data were analyzed as a factorial experiment in a completely randomized manner with three replication and each replication contained five heads using the JMP statistical software, version 5.1 (SAS Institute Inc., Cary, NC, USA). Sources of variation were storage time, treatments and their interaction. Means were compared by Student's ttest at a significance level of 0.05 .

\section{Results \\ Weight loss}

Weight loss of broccoli florets increased during storage period and speed of this increase course was affected by the treatments (Table 1). Weight loss of control and 1-MCP treated broccoli florets rapidly increased and at the end-point the control had lost $46.4 \%$ weight whereas the 1-MCP treated samples had lost $51.3 \%$ weight. In contrast, modified atmosphere packaging or 1-MCP+MAP significantly prevented weight loss of florets. The least weight loss occurred in MAP samples (10.8\%) followed by 1-MCP+MAP (11.2\%). 
Table 1. Effects of different postharvest treatments on soluble solid content (SSC) and titratable acidity (TA) of broccoli florets during cold storage at $0^{\circ} \mathrm{C}$.

\begin{tabular}{|c|c|c|c|c|c|c|}
\hline \multirow{2}{*}{ Parameter } & \multirow{2}{*}{ Treatments } & \multicolumn{5}{|c|}{ Days at $0^{\circ} \mathrm{C}$} \\
\hline & & Harvest & 7 & 14 & 21 & 28 \\
\hline \multirow{3}{*}{$\begin{array}{l}\operatorname{SSC}(\%) \\
\operatorname{LSD}_{0.05}=0.43\end{array}$} & Control & $5.9 \pm 0.115$ & $6.5 \pm 0.611$ & $8.5 \pm 0.458$ & $9.5 \pm 0.351$ & $10.1 \pm 0.000$ \\
\hline & 1-MCP & $5.9 \pm 0.115$ & $7.3 \pm 0.252$ & $8.1 \pm 0.231$ & $9.1 \pm 0.115$ & $8.9 \pm 0.000$ \\
\hline & MAP & $5.9 \pm 0.115$ & $6.2 \pm 0.058$ & $6.3 \pm 0.153$ & $6.2 \pm 0.252$ & $6.4 \pm 0.404$ \\
\hline \multirow{5}{*}{$\begin{array}{l}\text { TA (\%) } \\
\operatorname{LSD}_{0.05}=0.05\end{array}$} & 1-MCP+MAP & $5.9 \pm 0.115$ & $6.1 \pm 0.100$ & $6.1 \pm 0.153$ & $5.9 \pm 0.100$ & $6.4 \pm 0.436$ \\
\hline & Control & $0.90 \pm 0.047$ & $0.75 \pm 0.006$ & $0.67 \pm 0.072$ & $0.44 \pm 0.015$ & $0.45 \pm 0.035$ \\
\hline & 1-MCP & $0.90 \pm 0.047$ & $0.85 \pm 0.012$ & $0.70 \pm 0.000$ & $0.74 \pm 0.006$ & $0.70 \pm 0.031$ \\
\hline & MAP & $0.90 \pm 0.047$ & $0.76 \pm 0.010$ & $0.66 \pm 0.026$ & $0.54 \pm 0.044$ & $0.48 \pm 0.020$ \\
\hline & 1-MCP+MAP & $0.90 \pm 0.047$ & $0.80 \pm 0.006$ & $0.76 \pm 0.032$ & $0.71 \pm 0.012$ & $0.60 \pm 0.021$ \\
\hline \multirow{4}{*}{$\begin{array}{l}\text { Weight loss (\%) } \\
\text { LSD }_{0.05}=2.42\end{array}$} & Control & $0.00 \pm 0.000$ & $16.5 \pm 1.010$ & $29.3 \pm 1.075$ & $41.9 \pm 1.083$ & $51.3 \pm 0.185$ \\
\hline & 1-MCP & $0.00 \pm 0.000$ & $15.0 \pm 2.894$ & $26.6 \pm 3.526$ & $37.1 \pm 3.167$ & $46.5 \pm 2.596$ \\
\hline & MAP & $0.00 \pm 0.000$ & $3.1 \pm 0.212$ & $5.4 \pm 0.260$ & $7.2 \pm 0.736$ & $10.8 \pm 0.570$ \\
\hline & 1-MCP+MAP & $0.00 \pm 0.000$ & $3.4 \pm 0.130$ & $6.1 \pm 0.272$ & $8.5 \pm 0.566$ & $11.2 \pm 0.805$ \\
\hline
\end{tabular}

Each value represents the mean of three replicate samples. \pm represent the standard deviation of that mean.

\section{Surface color}

Figure 1 illustrates the changes in hue angle that indicates surface color during storage. At the beginning of the storage, hue angle of broccoli florets was measured as $132.0^{\circ}$ and this value rapidly decreased during the first 7 days. During storage, 1-MCP+MAP combination significantly delayed hue angle decline compared with single application of 1-MCP or MAP. At the end of storage, the highest hue angle value was measured in 1-MCP+MAP combination $\left(126.7^{\circ}\right)$, followed by $1-\operatorname{MCP}\left(123.9^{\circ}\right)$, MAP $\left(123.2^{\circ}\right)$ and control $\left(121.2^{\circ}\right)$.

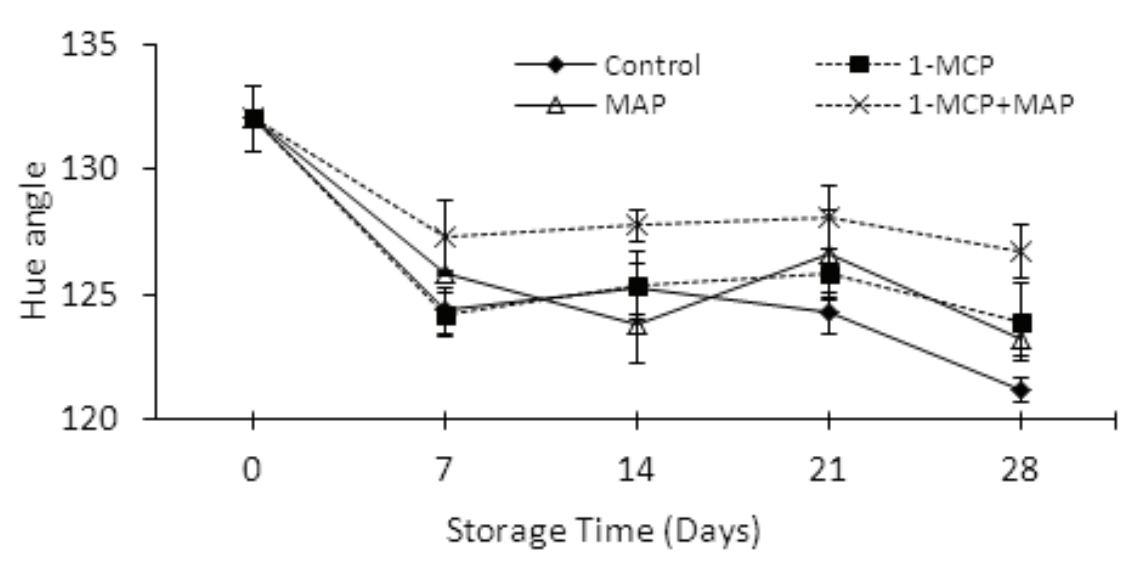

Fig. 1. Effects of different postharvest treatments on hue angle of broccoli florets during cold storage at $0{ }^{\circ} \mathrm{C}(\mathrm{LSD}=1.90, \mathrm{p}=0.0112)$. Each data point represents the mean of three replicate samples. Error bars represent the standard deviation of that mean. 


\section{Total phenol content}

Total phenol content of broccoli florets in most treatments sharply increased in the first 14 days of storage although it decreased afterwards and again increased up to 28th days, except for control (Fig 2). During storage, the highest total phenol content was determined in 1-MCP or combined treatment. Initial total phenol content of broccoli florets was $413.5 \mathrm{mg}_{\text {gallic acid }} \mathrm{kg}^{-1}$. At the end of the storage, the least total phenol content was obtained from control florets $\left(514.2 \mathrm{mg}_{\text {gallic acid }} \mathrm{kg}^{-1}\right.$ ) while the values of 1-MCP, MAP and 1-MCP+MAP treatments were 630.2 $\mathrm{mg}_{\text {gallic acid }} \mathrm{kg}^{-1}, 631.3 \mathrm{mg}_{\text {gallic acid }} \mathrm{kg}^{-1}$ and $638.5 \mathrm{mg}_{\text {gallic acid }} \mathrm{kg}^{-1}$, respectively.

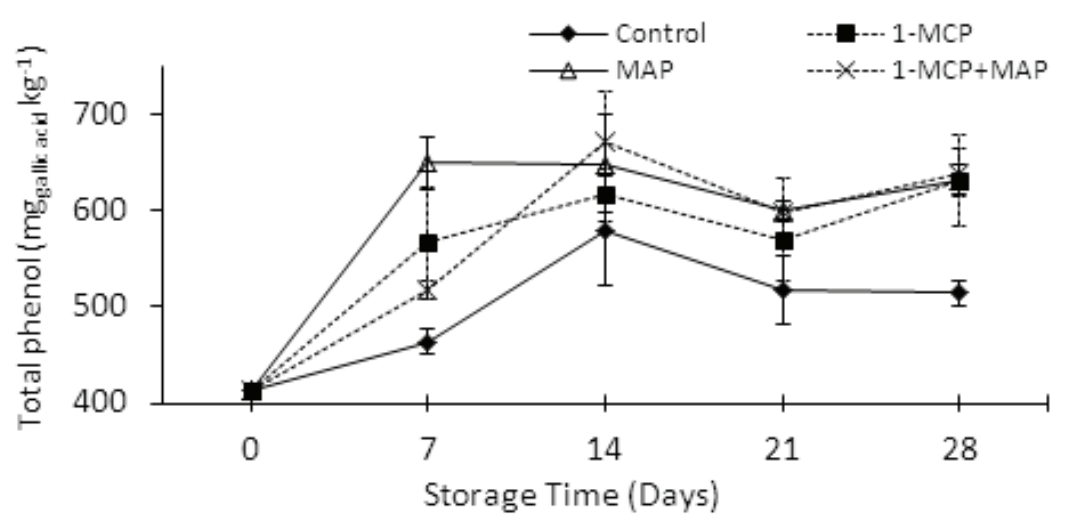

Fig. 2. Effects of different postharvest treatments on total phenol content of broccoli florets during cold storage at $0{ }^{\circ} \mathrm{C}(\mathrm{LSD}=53.85, \mathrm{p}=0.0009)$. Each data point represents the mean of three replicate samples. Error bars represent the standard deviation of that mean.

\section{Total chlorophyll}

Total chlorophyll content of broccoli florets decreased in all the treatments during storage at $0{ }^{\circ} \mathrm{C}$. However, chlorophyll degradation rate was significantly delayed by 1-MCP+MAP treatment (Fig. 3). Total chlorophyll amount of

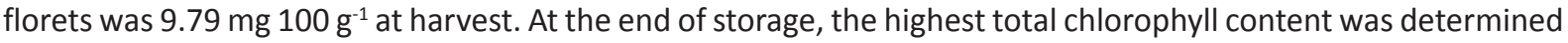

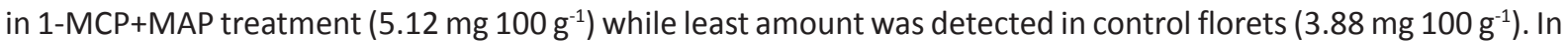
$1-\mathrm{MCP}+\mathrm{MAP}$ treated florets, $47 \%$ more chlorophyll was found compared to control florets. With respect to chlorophyll concentration, combined treatment was more effective than either 1-MCP or MAP treatments.

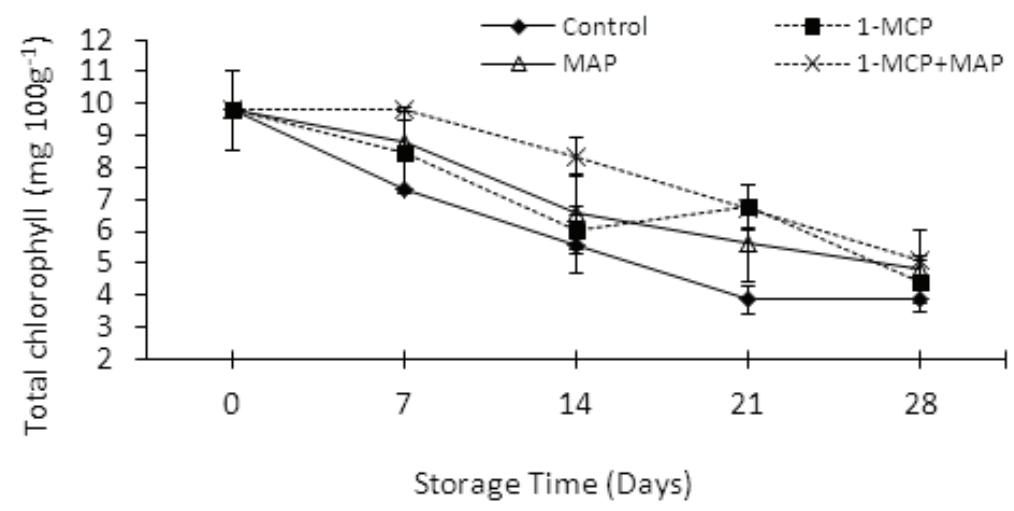

Fig. 3. Effects of different postharvest treatments on total chlorophyll of broccoli florets during cold storage at $0{ }^{\circ} \mathrm{C}(\mathrm{LSD}=1.45, \mathrm{p}=0.0417)$. Each data point represents the mean of three replicate samples. Error bars represent the standard deviation of that mean. 


\section{Ascorbic acid}

Changes in ascorbic acid amount of broccoli florets are illustrated in Figure 4. During the first 14 days of storage, no significant change was observed in ascorbic acid of florets in treated samples. At harvest, ascorbic acid amount

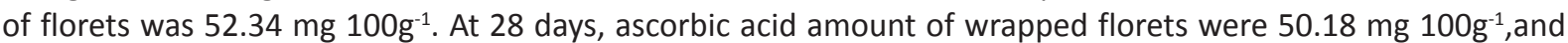

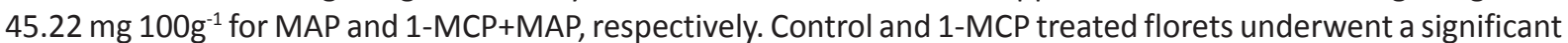

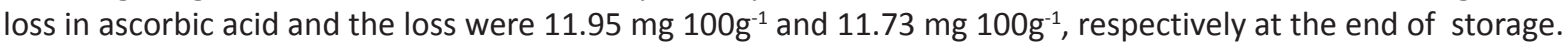

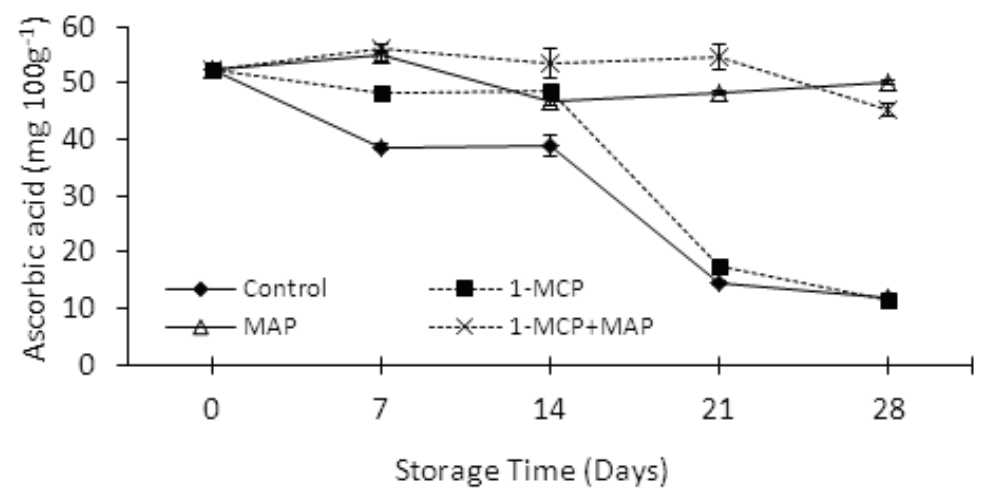

Fig. 4. Effects of different postharvest treatments on ascorbic acid content of broccoli florets during cold storage at $0{ }^{\circ} \mathrm{C}(\mathrm{LSD}=1.78, \mathrm{p}<0.0001)$. Each data point represents the mean of three replicate samples. Error bars represent the standard deviation of that mean.

\section{Visual quality and color}

Changes of visual quality and color in broccoli florets are illustrated in Figure 5A and B. Visual quality of all the florets decreased during storage and the decrease was most pronounced in control florets. MAP or 1-MCP+MAP significantly preserved the visual quality of florets. In addition, according to the visual quality assessment of the panelists, compactness of heads and hardness of stem texture were maintained in 1-MCP+MAP treated florets. Control florets reached to limit of marketability at $21 \mathrm{~d}$. At the end of storage, the best visual quality score was determined in 1-MCP+MAP (8.0) while control florets (4.3) markedly lost their visual quality feature.

A similar effect was apparent with respect to color of florets, evaluated using 1-5 scale. For 14 days of storage, no change was detected in visual color of florets treated with 1-MCP+MAP and MAP; while control and 1-MCP treated florets indicated slow color degradation. At $28 \mathrm{~d}$, color of control florets reached up to 3.7 score and this value is below the acceptable level. At $21 \mathrm{~d}$ score of florets belonging to 1-MCP+MAP treatment was determined as 1.3 by the panelists and the change in these florets was statistically significant (Fig. 5B).
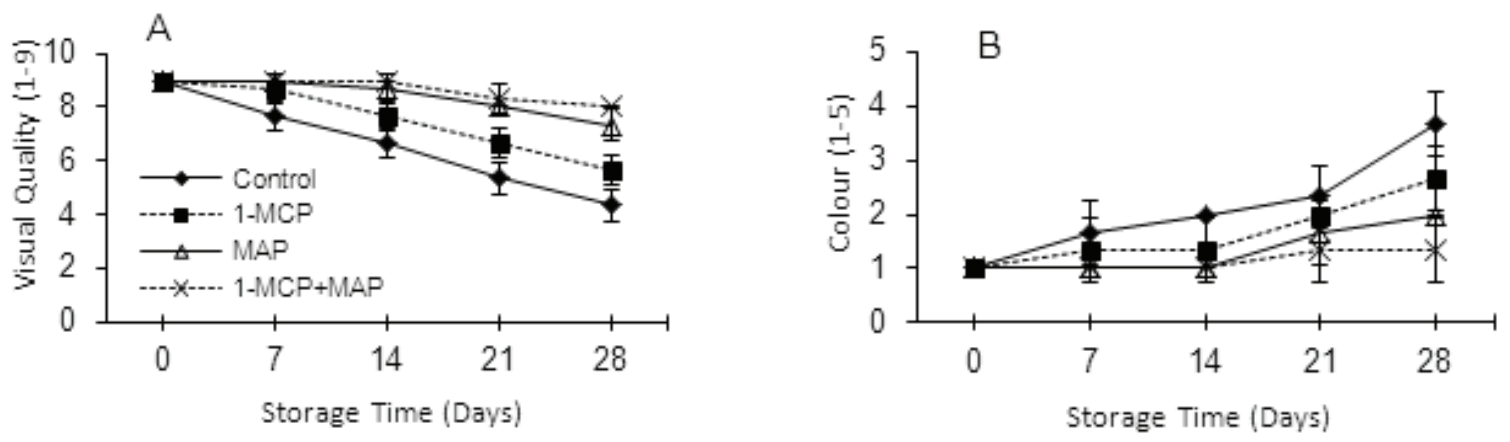

Fig. 5. Effects of different postharvest treatments on visual quality (A) and color (1-5 scale) (B) of broccoli florets during cold storage at $0{ }^{\circ} \mathrm{C}(\mathrm{LSD}=0.71, \mathrm{p}<0.0001$ for $\mathrm{A} ; \mathrm{LSD}=0.64, \mathrm{p}=0.0087$ for $\mathrm{B})$. Each data point represents the mean of three replicate samples. Error bars represent the standard deviation of that mean. 


\section{Titratable acidity (TA) and soluble solid content (SSC)}

Titratable acidity at harvest was $0.90 \%$ and this value decreased along with the prolonged storage. During the first 14 days of storage, the changes in TA content of florets were insignificant among the treatments. However, TA contents of MAP or control florets were significantly lower than the others at $21^{\text {th }}$ and $28^{\text {th }}$ days (Table 1). 1-MCP or 1-MCP+MAP treatments effectively maintained the TA levels of florets during storage at $0{ }^{\circ} \mathrm{C}$. At the end of storage, TA values ranged from $0.45 \%$ (control) to $0.70 \%$ (1-MCP).

SSC content of florets was $5.9 \%$ at the beginning of storage and increased along with storage. Such increase occurred sharply in control and 1-MCP treated florets, accompanying with the increase course in weight loss. At 28 days, the highest SSC was determined in control florets $(10.1 \%)$, followed by 1 -MCP $(8.9 \%), \operatorname{MAP}(6.4 \%)$ and 1-MCP+MAP (6.4\%).

\section{Discussion}

Yellowing of broccoli florets is an important quality loss during postharvest handling and storage. The increment in the activities of chlorophyll-degrading enzymes such as chlorophyllase, Mg-dechelatase or Mg-dechelation is responsible for senescence (Kaewsuksaeng 2011). Makhlouf et al. (1989) reported that broccoli is defined as climacteric produce due to its respiration ratio and ethylene production increasing during senescence leading to yellowing of florets. In the present study, 1-MCP treatments combined with modified atmosphere package prevented chlorophyll degradation and declined hue angle compared to other treatments including control florets. This effect may explain that 1-MCP+MAP treatment prevent ethylene rising and delay the onset of yellowing. Previous studies have demonstrated that 1-MCP and MAP combination significantly prevented color changes during storage in various horticultural crops such as broccoli (Kasim et al. 2007), litchi (De Reuck et al. 2009), persimmon (Kaynas et al. 2010) and tomato (Sabir and Agar 2011a).

Broccoli is a highly perishable product and its shelf life and visual quality are affected by various postharvest conditions (Jia et al. 2009). In this research, 1-MCP treatment obviously protected both visual quality (1-9 scale) and color (1-5 scale) features of wrapped florets. Combined use of 1-MCP with MAP significantly maintained compactness of heads and hardness of stem texture. Serrano et al. (2006) reported that stem texture was highly correlated with weight loss because tissue dehydration was accompanied by increases in elasticity. Our results also indicated that florets with little water loss had better appearance than florets with a high water loss, and lowloss florets had maximum shelf life.

High weight loss is a significant problem of stored broccoli florets which affect the marketability (Serrano et al. 2006). MAP or 1-MCP+MAP significantly reduced weight loss. Similar results were also reported by Carvalho and Clemente (2004), Tano et al. (2007), Jia et al. (2009), Nath et al. (2011) on MAP used broccoli. Besides, Kasim et al. (2007) reported that combined use of 1-MCP treatment with polyvinylchloride film package reduced weight loss of broccoli heads compared with other films. MAP is an effective tool for reducing weight loss due to its inhibition of water vapour diffusion and thus it generates a water vapour pressure and higher relative humidity inside the package (Serrano et al. 2006, Jia et al. 2009). This effect of MAP is also widely used for successful storage of other vegetables such as tomato (Batu and Thompson 1998, Moretti et al. 2005, Sabir and Agar 2010), cauliflower (Mekwatanakarn 1999), spinach and parsley (Zenoozian 2011) and dill leaves (Sakaldas et al. 2010).

Phenolics and ascorbic acid are compounds involved in the maintenance of antioxidant status (Lemonie et al. 2007). Broccoli is proven as a very important source of phenolic compounds. Bahorun et al. (2004) characterized the broccoli as possessing a significantly high level phenol (higher than $800 \mu \mathrm{g} \mathrm{g}^{-1}$ ) amongst ten different vegetables. The amounts of nutritional compounds such as total phenol, ascorbic acid and antioxidants were reported to vary among different cultivars, climactic conditions, cultural practices, stage of maturity and postharvest handling and storage (Sivakumar et al. 2012). In this study, total phenol content in treated florets were higher than control florets during storage. This result is in agreement with that of Lemonie et al. (2010) who reported higher total phenol in UV-C+heat air treated florets than control ones.

Vitamin $\mathrm{C}$ is one of the most important vitamins in fruits and vegetables for human nutrition and its concentrations in horticultural commodities is fundamentally affected by various factors such as handling and storage conditions (temperature, controlled atmosphere or modified atmosphere packaging and various postharvest applications) (Lee and Kader 2000). Broccoli is rich in health-promoting compounds such as ascorbic acid and the 
amount of these compounds decrease during storage (Serrano et al. 2006). Present study revealed that MAP or 1-MCP+MAP significantly prevented loss in ascorbic acid content. According to the recent studies conducted on different cultivars with distinct conditions, MAP was significantly effective to prevent ascorbic acid loss in broccoli (Serrano et al. 2006, Carvalho and Clemente 2004). Nath et al. (2011) reported that broccoli heads packaged with polypropylene (PP) film having 10 pin holes showed less ascorbic acid loss than unwrapped samples in refrigerated storage. Similarly, Yuan et al. (2010) reported that 1-MCP treatment significantly minimized loss of ascorbic acid in broccoli florets. However in our study, 1-MCP treatment was ineffective for preventing loss of ascorbic acid in broccoli florets while 1-MCP+MAP resulted in better retention of ascorbic acid during prolonged storage. These results are in accordance with earlier report where positive impacts of combined use of 1-MCP with chitosan coating in Indian jujube fruits (Qiuping and Wenhui 2007) and 1-MCP with controlled atmosphere $\left(3 \% \mathrm{O}_{2}+\right.$ $8 \% \mathrm{CO}_{2}$ ) in mango (Sivakumar et al., 2012) were investigated.

In conclusion, MAP and 1-MCP combined treatment prevented losses of green color (either chlorophyll breakdown or hue angle decline), ascorbic acid and total phenol content and these florets exhibited significantly less weight loss at $0{ }^{\circ} \mathrm{C}$ and $95 \% \mathrm{RH}$ that control florets. Therefore, combined treatment could be recommended to use for maintaining the postharvest quality of broccoli florets.

\section{References}

Aharoni, N., Philosoph-Hadas, S. \& Barkai-Golan, R. 1985. Modified atmospheres to delay senescence and decay of broccoli. Proceedings of the 4th National Controlled Atmosphere Research Conference, North Carolina Horticulture Report No. 126. Dept. of Hort. Sci., Raleigh, N.C. Hort. Rpt. 126. p. 169-177.

Bahorun, T., Luximon-Ramma, A., Crozier, A. \& Aruoma, O.I. 2004. Total phenol, flavonoid, proanthocyanidin and vitamin C levels and antioxidant activities of Mauritian vegetables. Journal of the Science of Food and Agriculture 84: 1553-1561.

Batu, A. \& Thompson, A.K. 1998. Effects of modified atmosphere packaging on post harvest qualities of pink tomatoes. Turkish Journal of Agriculture and Forestry 22: 365-372.

Blankenship, S.M. \& Dole, J.M. 2003. 1-methylcyclopropene: A review. Postharvest Biology and Technology 28: 1-25.

Carvalho, P.T. \& Clemente, E. 2004. The influence of the broccoli (Brassica oleracea var. italica) fill weight on postharvest quality. Ciência e Tecnologia de Alimentos 24: 646-651.

Cefola, M., Amodio, M.L., Rinaldi, R., Vanadia, S. \& Colelli, G. 2010. Exposure to 1-methylcyclopropene (1-MCP) delays the erects of ethylene on fresh-cut broccoli raab (Brassica rapa L.). Postharvest Biology and Technology 58: 29-35.

De Reuck, K., Sivakumar, D. \& Korsten, L. 2009. Integrated application 1-methylcyclopropene and modified atmosphere packaging to improve quality retention of litchi cultivars during storage. Postharvest Biology and Technology 52: 71-77.

Fan, X. \& Mattheis, J.P. 2000.Yellowing of broccoli in storage is reduced by 1-methylcyclopropene. HortScience 35: 885-887.

Forney, C.F., Song, J., Fan, L., Hildebrand, P.D. \& Jordan, M.A. 2003. Ozone and 1-methylcyclopropene alter the postharvest quality of broccoli. Journal of the American Society for Horticultural Science 128: 403-408.

Jia, C.G., Xu, C.J., Wei, J., Yuan, J., Yuan, G.F., Wang, B.L \& Wang, Q.M. 2009. Effect of modified atmosphere packaging on visual quality and glucosinolates of broccoli florets. Food Chemistry 114: 28-37.

Jiang, Y., Joyce, D.C. \& Macnish, A.J. 1999. Extension of the shelf life of banana fruit by 1-methylcyclopropene in combination with polyethylene bags. Postharvest Biology and Technology 16: 187-193.

Kaewsuksaeng, S. 2011. Chlorophyll degradation in Horticultural crops. Walailak Journal of Science and Technology 8: 9-19.

Kasim, R., Kasim, M.U. \& Erkal, S. 2007. The effect of packaging after 1-MCP treatment on color changes and chlorophyll degradation of broccoli (Brassica oleracea var. italic acv. Monopoly). Journal of Food Agriculture \& Environment 5: 48--51.

Kaynas, K., Sakaldas, M., Kuzucu, F.C. \& Bicen, E. 2010. The combined effects of 1- Methylcyclopropene and modified atmosphere packaging on fruit quality of 'Fuyu' persimmon fruit during storage. Acta Horticulturae 876: 151-158.

Ku, V.V.V. \& Wills, R.B.H. 1999. Effect of 1- methylcyclopropene on the storage life of broccoli. Postharvest Biology and Technology 17: 127-132.

Lancaster, J.E., Lister, C.E., Reay, P.F. \& Triggs, C.M. 1997. Influence of pigment composition on skin color in wide range of fruits and vegetables. Journal of the American Society for Horticultural Science 122: 594-598.

Lee, S.K. \& Kader, A.A. 2000. Preharvest and postharvest factors influencing vitamin C content of horticultural crops. Postharvest Biology and Technology 20: 207-220.

Lemoine, M.L., Civello, P.M., Chaves, A.R. \& Martinez, G.A. 2010. Influence of a combined hot air and UV-C treatment on quality parameters of fresh-cut broccoli florets at $0^{\circ} \mathrm{C}$. International Journal of Food Science and Technology 45: 1212-1218.

Makhlouf, J.C., Willemot, J., Arul, F., Castaigne, F. \& Emond, J. 1989. Regulation of ethylene biosynthesis in broccoli flower buds in controlled atmospheres. Journal of the American Society for Horticultural Science 114: 955-958.

Mekwatanakarn, W. 1998. Modified atmosphere packaging of vegetables. USA: Oregon State University, PhD thesis. 178 p..

Moretti, C.L., Mattos, L.M., Berg, F.L.N. \& Santos, J.Z. 2005. Quality attributes of tomatoes submitted to different postharvest treatments. Acta Horticulturae 682: 1029-1035. 
Nath, A., Bagchi, B., Misra, L.K.\& Deka, B.C. 2011. Changes in post-harvest phytochemical qualities of broccoli florets during ambient and refrigerated storage. Food Chemistry 127: 1510-1514.

Nestle, M. 1998. Broccoli sprouts in cancer prevention. Nutrition Reviews 56: 127-130.

Oz, A.T. 2011. Combined effects of 1-methyl cycloproene (1-MCP) and modified atmosphere packaging (MAP) on different ripening stages of persimmon fruit during storage. African Journal of Biotechnology 10: 807-814.

Ozdemir, A.E. \& Dundar, O. 2006. The effects of fungicide and hot water treatments on the internal quality parameters of Valencia oranges. Asian Journal of Plant Science 5: 142-146.

Qiuping, Z. \& Wenshui, X. 2007. Effect of 1-methylcyclopropene and /or chitosan coating treatments on storage life and quality maintenance of Indian jujube fruit. LWT 40: 404-411.

Rangavajhyala, N., Ghorpade, V.M. \& Kadam, S.S. 1998. Broccoli. In: D.K. Salunkhe \& S.S. Kadam (eds.). Handbook of Vegetable Science and Technology: Production, Storage and Processing. New York : Marcel Dekker .(, p. 337-357. ,.

Sabir, F.K. \& Agar, I.T. 2010. Effects of modified atmosphere packaging on postharvest quality and storage of mature green and pink tomatoes. Acta Horticulturae 876: 201-207.

Sabir, F.K. \& Agar, I.T. 2011a. Effects of 1-metyhlcycloproepene and modified atmosphere packaging on postharvest life and quality in tomatoes. Journal of Food Quality 34: 111-118

Sabir, F.K. \& Agar, I.T. 2011b. Influence of different concentrations of 1-methylcyclopropene on the quality of tomato harvested at different maturity stages. Journal of the Science of Food and Agriculture 91: 2835-2843.

Sakaldas, M., Aslım, A.S., Kuzucu, C.Ö. \& Kaynaş, K. 2010. The effect of modified atmospherepackaging and storage temperature on quality and biochemical properties of dill (Anethum graveolens) leaves. Journal of Food Agriculture \& Environment 8: 21-25.

Serrano, M., Martinez-Romero, D., Guillén, F., Castillo, S. \& Valero, D. 2006. Maintenance of broccoli quality and functional properties during cold storage as affected by modified atmosphere packaging. Postharvest Biology and Technology 39: 61-68.

Singleton, V.L., Orthofer, R., Lamuela-Ravento, R.M. 1999. Analysis of total phenols and other oxidation substrates and antioxidants by means of Folin-Ciocalteu reagent. In: Packer, L. (ed.). Methods in enzymology. p. 152-178

Sivakumar, D., Van Deventer, F., Terry, L.A., Polanta G.A. \& Korsten L. 2012. Combination of 1-methylcyclopropene treatment and controlled atmosphere storage retains overall fruit quality and bioactive compounds in mango. Journal of the Science of Food and Agriculture 92: 821-830.

Tano, K., Oule, M.K., Doyon, G., Lencki, R.W. \& Arul, J. 2007. Comparative evaluation of the effect of storage temperature fluctuation on modified atmosphere packages of selected fruit and vegetables. Postharvest Biology and Technology 46: 212-221.

Thompson, A.K. 2003. Fruit and vegetables Harvesting, Handling and storage. Oxford, UK:Blackwell Publishing..278 p.

Tian, M.S., Down, C.G., Lill, R.E. \& King, G.A. 1994. A role of ethylene in the yellowing of broccoli after harvest. Journal of the American Society for Horticultural Science 119: 276-281.

Vallejo, F., Tomas-Barberan, F. A., \& Garcia-Viguera, C. 2003. Health-promoting compounds in broccoli as influenced by refrigerated transport and retail sale period. Journal of Agricultural and Food Chemistry 51: 3029-3034.

Vasconcelos, I.S.A. \& Almeida, D.P.F. 2003. Treatment with 1-methylcyclopropene complements temperature management in maintaining postharvest quality of broccoli. Acta Horticulturae 628: 227-232.

Wang, C.Y. 1977. Effect of aminoethoxy analog of rhizobitoxine and sodium benzoate on senescence of broccoli. HortScience 12 : 54-56.

Yuan, G., Sun, B., Yuan, J. \& Wang, Q. 2010. Effect of 1-methylcyclopropene on shelf life, visual quality, antioxidant enzymes and health-promoting compounds in broccoli florets. Food Chemistry 118: 774-781.

Zenoozian, M.S. 2011. Combined effect of packaging method and temperature on the leafy vegetables properties. International Journal of Environmental Science and Development 2: 124-127. 